\title{
Resection of retrohepatic inferior vena cava without reconstruction in ex vivo liver resection and autotransplantation: a retrospective study
}

\author{
Xianwei Yang ${ }^{1}$, Tao Wang ${ }^{1}$, Junjie Kong ${ }^{1}$, Bin Huang ${ }^{2}$ and Wentao Wang ${ }^{1 *}$
}

\begin{abstract}
Background: Retrohepatic inferior vena cava (RIVC) resection without reconstruction in ex vivo liver resection and autotransplantation (ERAT) for advanced alveolar echinococcosis (HAE) is unclear.

Methods: This is a retrospective study of consecutive patients referred to our hospital from 2014 to 2018. Depending on the presence of a rich collateral circulation and stable blood volume in ERAT, patients did not rebuild the RIVC. Then, patients were selected some appropriate revascularization techniques for the hepatic and renal veins. Finally, all ERAT procedures were completed, and short- and long-term outcomes were observed.

Results: Five advanced HAE patients underwent ERAT without RIVC reconstruction. One patient died of circulatory failure 1 day after surgery. Another four patients, with a median follow-up duration of 18 months (range, 10-25 months), demonstrated normal liver and kidney function, no thrombosis and no HAE recurrence.

Conclusions: Through the long-term results of ERAT, the pros and cons of not reconstructing the RIVC need to be re-examined. In cases with a rich collateral circulation, the RIVC cannot be reconstructed. However, in cases requiring the resection of multiple organs, RIVC without reconstruction was prudential.
\end{abstract}

Keywords: Hepatic alveolar echinococcosis, Inferior vena cava, Liver autotransplantation, Reconstruction

\section{Background}

Intraabdominal inferior vena cava (IVC) resection is a very challenging task. When the IVC is invaded by primary or secondary lesions of the liver, the hepatic tumors and the retrohepatic inferior vena cava (RIVC) should be treated simultaneously $[1,2]$. Correspondingly, protecting blood flow in the portal system, kidneys and lower limbs is also challenging. Ex vivo liver resection and autotransplantation (ERAT) has become a hot topic in recent years [3], especially in the study of benign liver

\footnotetext{
* Correspondence: wwtdoctor02@163.com

'Department of Liver Surgery \& Liver Transplantation Center, West China Hospital of Sichuan University, 37 Guoxue Road, Chengdu 610041, P. R. China Full list of author information is available at the end of the article
}

diseases. An increasing number of new ideas support the superior long-term efficacy of ERAT in treating hepatic alveolar echinococcosis (HAE) or benign liver tumors compared to that of allogeneic liver transplantation [4, 5]. In patients with HAE with partial or complete occlusion of the RIVC before surgery, if the imaging evaluation shows a rich collateral circulation, RIVC reconstruction may not be performed according to the actual situation [2]. However, there have been few relevant previous studies and no long-term outcome studies, and most related studies have examined primary IVC tumors [6, 7]. This study analyzed the technical features and short-term and long-term results of RIVC resection

(c) The Author(s). 2020 Open Access This article is licensed under a Creative Commons Attribution 4.0 International License, which permits use, sharing, adaptation, distribution and reproduction in any medium or format, as long as you give appropriate credit to the original author(s) and the source, provide a link to the Creative Commons licence, and indicate if changes were made. The images or other third party material in this article are included in the article's Creative Commons licence, unless indicated otherwise in a credit line to the material. If material is not included in the article's Creative Commons licence and your intended use is not permitted by statutory regulation or exceeds the permitted use, you will need to obtain permission directly from the copyright holder. To view a copy of this licence, visit http://creativecommons.org/licenses/by/4.0/ The Creative Commons Public Domain Dedication waiver (http://creativecommons.org/publicdomain/zero/1.0/) applies to the data made available in this article, unless otherwise stated in a credit line to the data. 
without reconstruction in ERAT in a 2-year follow-up study at our center.

\section{Methods}

From February 2014 to August 2018, a total of $280 \mathrm{HAE}$ patients underwent surgical treatment at our Medical Center, West China Hospital of Sichuan University, and the medical records were retained. Seventy-seven patients (27.5\%) with advanced HAE underwent ERAT, and the RIVC was not reconstructed in five of them (6.5\%). Table 1 showed the clinical characteristics and imaging findings of these 5 patients.

The study was approved by the Ethics Committee of West China Hospital of Sichuan University (No. 201738) and conducted in accordance with the Declaration of Helsinki. All patients and their families signed informed consent and surgical consent before surgery. Calculation of the mean, median, range, and frequency was performed with statistical Excel 2016 software (Microsoft, Redmond, WA, USA).

\section{Surgical technique}

The surgical indications for ERAT were consistent with our previous reports [2], and five patients first met this criterion. Based on the location of the HAE lesions, residual liver function, kidney function, and the assessment of extrahepatic organs (e.g., lungs and brain, Fig. 1a), after a multidisciplinary team discussion, we prepared a plan preoperatively for not reconstructing the RIVC in these 5 patients. Preoperative IVC angiography and ultrasound were used to assess the collateral circulation (Fig. 1b). Artificial blood vessels (InterGard, InterVascular SAS, Inc., La Ciotat, France) were prepared for these patients if IVC vascular replacement was needed. The Mercedes incision was used to enter the abdominal cavity, fully exposing the liver, hilar structure and IVC. Due to the large size of the HAE lesions, it was often necessary to remove some of the diaphragm and empty the gastrointestinal tract. The treatment of the hepatic artery, portal vein, bile duct and other vessels has been detailed in a previous report $[2,8]$. In five patients, ex vivo liver resection and back-table reshaping was performed to obtain healthy liver grafts. Then, the patients entered the anhepatic phase.

In the anhepatic phase, a temporary portocaval shunt was used in 3 patients because these patients showed slight intestinal congestion. The ex vivo liver resection was simultaneously performed by another group of surgeons. The liver was perfused with $4-8 \mathrm{~L}$ of $0-4{ }^{\circ} \mathrm{C}$ HTK solution (histidine-tryptophan-ketoglutarate, Custodiol ${ }^{\circ}$, Dr. Franz Kohler Chemie, Germany) via the PV while cooled in ice bath. Parenchymal transection was performed with a minimum 1.0-cm lesion-free margin using the Cavi-Pulse Ultrasonic Surgical Aspirator (CUSA, Valleylab, Boulder, CO, USA). In patients 1 and 2, temporary artificial blood vessels were used instead of the RIVC. Finally, in patient 1 , only the artificial blood vessels in the left hepatic vein and the suprahepatic IVC junction were retained, while in patient 2 , the artificial vessels were all discarded after the suprarenal IVC was closed. In patient 4, the shaped suprarenal IVC and the end of the left renal vein were directly anastomosed (Fig. 1c). Because HAE invaded the right kidney in patient 4 , it could not be preserved and needed to be removed. Ligation of the right renal vein was possible due to the existence of a rich collateral circulation through the left renal, adrenal and gonadal veins. In all patients, the hemodynamics and urine volume remained stable, without intestinal congestion after RIVC clamping (duration, over $30 \mathrm{~min}$ ) or end-toend anastomosis, particularly when the patients had thriving ascending lumbar veins, an adequate hemiazygos, or large portosystemic collaterals. See Figure S1 for details of the other operations characteristics of the 5 patients.

In patients 1 and 3 , the suprahepatic IVC was anastomosed after the great saphenous vein was used to shape the left hepatic vein (enlarged outflow tract). Anastomosis was carried out using running sutures of $5-0$

Table 1 The clinical characteristics and imaging findings of the 5 patients

\begin{tabular}{|c|c|c|c|c|c|c|c|c|c|c|}
\hline Case & $\begin{array}{l}\text { Age/ } \\
\text { Sex }\end{array}$ & $\begin{array}{l}\mathrm{BMI}, \\
\mathrm{kg} / \mathrm{m}^{2}\end{array}$ & Chief complaint & $\begin{array}{l}\text { PNM } \\
\text { stage }\end{array}$ & $\begin{array}{l}\text { Diameter, } \\
\mathrm{cm}\end{array}$ & $\begin{array}{l}\text { Pre-ERAT } \\
\text { Treatment* }\end{array}$ & $\begin{array}{l}\text { Estimated } \\
\operatorname{RLV}(\mathrm{mL})\end{array}$ & $\begin{array}{l}\text { Autograft } \\
\text { mass }(\mathrm{g})\end{array}$ & $\begin{array}{l}\text { Follow up, } \\
\text { months }\end{array}$ & $\begin{array}{l}\text { Current } \\
\text { status }\end{array}$ \\
\hline 1 & $32 / \mathrm{M}$ & 17.7 & $\begin{array}{l}\text { Upper abdominal pain, } 2 \\
\text { years }\end{array}$ & P4N1M0 & 14.1 & PTCD & 600 & 565 & 25 & Alive \\
\hline 2 & $41 / F$ & 21.5 & $\begin{array}{l}\text { Upper abdominal pain, } 4 \\
\text { months }\end{array}$ & P4N1M0 & 16.5 & Hepatectomy & 900 & 880 & 24 & Alive \\
\hline 3 & $22 / F$ & 20.9 & Liver lesion growth, 1 year & P4N1M0 & 9.2 & Hepatectomy & 450 & 380 & 13 & Alive \\
\hline 4 & $44 / F$ & 18.8 & $\begin{array}{l}\text { Liver mass, } 12 \text { years; } \\
\text { jaundice, } 2 \text { months }\end{array}$ & P4N1M1 & 14.0 & PTCD & 750 & 700 & - & Dead \\
\hline 5 & $26 / F$ & 24.2 & Liver lesion growth, 1 year & P4N1M1 & 11.2 & No & 750 & 730 & 10 & Alive \\
\hline
\end{tabular}

BMI Body mass index, PNM stage the classifications $\mathrm{P}$ (parasitic in the liver), $\mathrm{N}$ (extension to neighboring organs), and $\mathrm{M}$ (distant metastasis) were developed by the European Echinococcosis Registry Network of the WHO Informal Working Group on Echinococcosis, ERAT ex vivo liver resection and autotransplantation, PTCD percutaneous transhepatic cholangial drainage, RLV remnant liver volume (preoperative measurement by CT images). Patient 4 died 1 day after surgery, so there was no follow up. "*" refered to the pre-ERAT treatment measures, not the current admission (ERAT), and the interval was at least 2 months. Gender, age and clinical data of the patients were available 

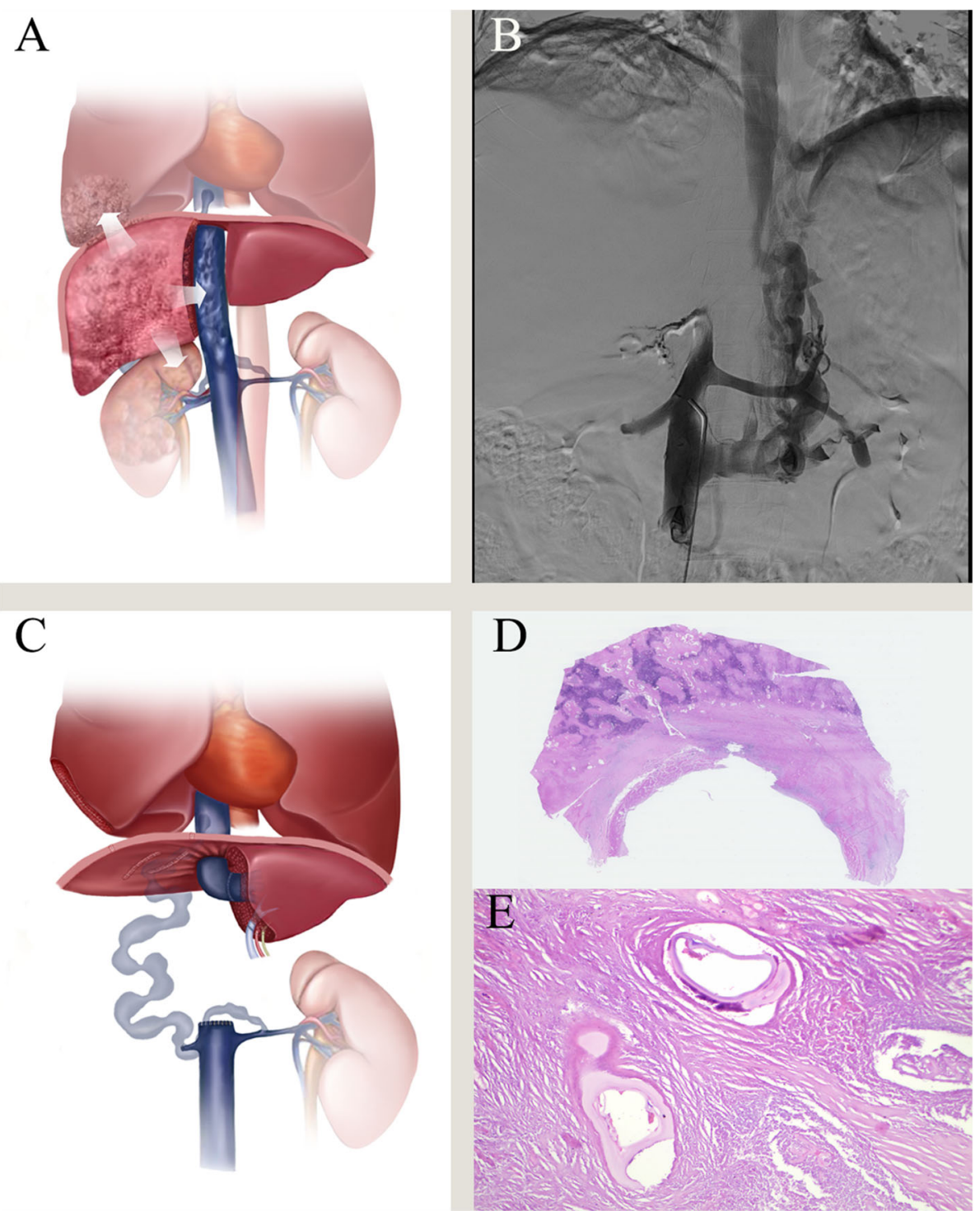

Fig. 1 The main techniques for retrohepatic inferior vena cava (RIVC) resection without reconstruction in ex vivo liver resection and autotransplantation (ERAT). a preoperative simulation of the extent of hepatic alveolar echinococcosis, including the right lower lung lobe and right kidney. b preoperative inferior vena cava angiography shows the rich collateral circulation and right renal vein, retrohepatic inferior vena cava occlusion. c diagram of reconstruction of patient 4 after liver autotransplantation. $\mathbf{d}$ histological section of the all layers of RIVC showing a granulomatous inflammation with a necrotic center induced by Echinococcus multilocularis. Hematoxylin-eosin staining, $\times 0.37$. e remnants of laminated layer of E. multilocularis. Hematoxylin-eosin staining, $\times 400$. Figure $\mathbf{a}$ and $\mathbf{c}$ were draft completed by Xianwei Yang and the final draft completed in Adobe Photoshop CS6 (Serial number: 1330-1152-1635-8311-0579-3839). These figure 1a-e belongs to the authors, and editing is allowed

Prolene. The left hepatic artery was reconstructed in an end-to-end manner to a size-matched branch of the hepatic artery, and duct-to-duct biliary anastomosis was performed in all patients. The anastomosis of these vessels was completed after the intraoperative ultrasound monitoring of hemodynamics was normal. After repeated examination of the abdominal cavity, two drainage tubes were placed, and the abdominal cavity was closed satisfactorily. Immediately after the infected IVC and liver lesions were removed, they were placed in $10 \%$ formaldehyde, routinely dehydrated, embedded in paraffin, sliced into $4 \mu \mathrm{m}$ sections, and hematoxylin and eosin (HE) was performed. The diagnosis was based on the presence or absence of small particles of E. multilocularis (spems) outside the main lesion under the microscope.

\section{Postoperative management and follow-up observations}

After the operation, the patient was admitted to the intensive care unit and returned to the general ward after 
recovering vital signs. No antirejection drugs or anticoagulant drugs were needed after the surgery. All patients were administered preferentially albendazole (15 $\mathrm{mg} / \mathrm{kg} /$ day) routinely for 1 year after ERAT [9]. Albendazole was stopped if patients showed adverse events (including hypersensitivity, drug-induced liver injury, intolerance, or allergy), change the dosage form, or take the medicine 2 months after the side effect disappears. Short-term ( $<90$ days) and long-term postoperative complications were identified and treated. The patients were followed every 3-6 months after discharge.

\section{Results}

We retrospectively collected 5 HAE patients (4 women, 1 man) who underwent ERAT without RIVC reconstruction (Table 1). The mean age of these patients was 33 years (range, 22-44 years). The chief complaint was upper abdominal pain, which was observed in 2 patients. Among the patients, patients 1 and 4 showed obstructive jaundice due to lesion compression, and they underwent percutaneous transhepatic cholangial drainage (PTCD) to reduce the total bilirubin level before admission.

The median operative duration was 859 min (range, 600-1290 min), and the anhepatic period was $326 \mathrm{~min}$ (range, 197-440 min). The median blood loss was 4140 $\mathrm{ml}$, and the range was $2200-800 \mathrm{ml}$. Postoperative pathology was confirmed as HAE, and RIVC was violated in the whole layer (Fig. 1d, e). The average postoperative hospital stay was 21 days (range, 1-47 days). Short-term complications included one case of mortality (patient 4) due to circulatory failure 1 day after surgery and two cases of bile leakage (patients 3 and 5), which disappeared after 14 days abdominal drainage. Hepatic vein stenosis occurred in patient 2 at 6 months after the surgery and was relieved after stent implantation. Patient 3 showed sacral effusion in the liver at 5 months after the surgery and finally underwent puncture under ultrasound guidance, which indicated biliary cysts. Postoperative IVC angiography showed that the suprarenal IVC was completely blocked and multiple collateral circulation routes had been established. The intra- and postoperative characteristics and complications are summarized in Table 2. None of the 4 surviving patients showed HAE recurrence and were alive with a patent collateral circulation after a median follow-up period of 18 (range, $10-25$ years) months.

\section{Discussion}

Like IVC leiomyosarcoma, many benign or malignant lesions of the liver that invade the IVC are challenging to treat [7]. Echinococcosis is a benign parasitic disease that is mainly transmitted through the "fecal-mouth" route (digestive tracts). Because most of the epidemic areas are in high-altitude Tibetan areas (average elevation of $4200 \mathrm{~m}$ ), medical resources are scarce, education levels are low, and many patients are in advanced stages of treatment, and HAE is more severe than cystic hydatid disease $[10,11]$. HAE is a seriously neglected parasitic disease that is also known as worm cancer [11, 12]. When the hepatic echinococcosis lesion is huge, it often invades the inferior vena cava [13]. Unlike liver tumor biology (eg, primary liver cancer, hilar cholangiocarcinoma), HAE is a benign disease that is not in an irreparable state when it invades vital blood vessels and organs. Because the palliative treatment and /or anti-infective treatment (oral albendazole tablets) doesn't achieve the desired results, surgery is the primary treatment for advanced HAE $[2,14]$.We describe 5 cases of HAE with a blocked RIVC treated with RIVC resection without reconstruction. Although the surgical technique might be a feasible and safe method for HAE patients with an adequate collateral circulation, the surgical outcome also deserves reflection. AE is close to the normal IVC outer membrane layer, mainly chronic granulomatous inflammation, accompanied by a large accumulation of lymphocyte, gradually manifested as chronic fibrosis, forming an inflammatory response zone. This is similar to liver AE lesions. For ERAT without reconstructing

Table 2 Intra- and postoperative characteristics and complications

\begin{tabular}{|c|c|c|c|c|c|c|c|c|c|}
\hline Case & $\begin{array}{l}\text { OP time } \\
\text { (min) }\end{array}$ & $\begin{array}{l}\text { Anhepatic } \\
\text { phase (min) }\end{array}$ & $\begin{array}{l}\text { Blood } \\
\text { loss (ml) }\end{array}$ & $\begin{array}{l}\text { Transfusion } \\
\text { (RBC units) }\end{array}$ & $\begin{array}{l}\text { RIVC } \\
\text { length } \\
(\mathrm{cm})\end{array}$ & $\begin{array}{l}\text { RIVC } \\
\text { circumference }\end{array}$ & $\begin{array}{l}\text { Short-term } \\
\text { complication }\end{array}$ & $\begin{array}{l}\text { Long-term } \\
\text { complication }\end{array}$ & $\begin{array}{l}\text { Complication } \\
\text { management }\end{array}$ \\
\hline 1 & 720 & 304 & 4000 & 20 & 6 & 360 & - & - & - \\
\hline 2 & 905 & 428 & 2200 & 10 & 7 & 270 & $\begin{array}{l}\text { Abdominal } \\
\text { cavity effusion }\end{array}$ & $\begin{array}{l}\text { Hepatic vein stenosis, } \\
\text { repeated ascites }\end{array}$ & $\begin{array}{l}\text { Stent } \\
\text { implantation }\end{array}$ \\
\hline 3 & 780 & 260 & 3000 & 6 & 8 & 360 & Bile leakage & Bile cyst & $\begin{array}{l}\text { Puncture } \\
\text { drainage }\end{array}$ \\
\hline 4 & 1290 & 440 & 8000 & 28 & 8 & 360 & $\begin{array}{l}\text { Circulatory } \\
\text { failure, death }\end{array}$ & - & - \\
\hline 5 & 600 & 197 & 3500 & 8 & 7 & 300 & $\begin{array}{l}\text { Bile duct } \\
\text { stricture }\end{array}$ & - & ERCP, ENBD \\
\hline
\end{tabular}

$O P$ operative, $R B C$ red blood cell, $R I V C$ retrohepatic inferior vena cava, $E R C P$ endoscopic retrograde cholangiopancreatography, $E N B D$ endoscopic nasal biliary drainage 
IVC, it is not necessary to accurately describe the inflammation of these lesions. We are more concerned about the degree of stenosis (perimeter) and length of invasion of the IVC. If the stenosis is lighter and shorter, this complicated operation is not necessary. Using local resection and reconstruction of IVC is sufficient [15].

For a long time, the RIVC has been considered to not require reconstruction if there is a rich collateral circulation $[4,7]$. According to this view, we did not the reconstruct RIVC in 5 patients. Patient 2 developed postoperative hepatic vein stenosis, mainly due to anastomotic stenosis associated with the suprahepatic IVC; however, the death of patient 4 was considered to be closely related to the lack of RIVC reconstruction. Due to the large volume of blood loss during surgery, the blood volume was supplemented by multiple venous channels after surgery, but the circulation still could not compensate for the circulatory failure, eventually leading to death. At this time, through the bridge of the RIVC and the left renal vein, the collateral circulation and the blood flow in the lower limbs was insufficient for the heart. The response to angiotensin and antishock drugs was also insufficient. In addition, patient 4 underwent right lung lobectomy, right nephrectomy, and liver graft resection, which was another factor contributing to the slow postoperative recovery. Therefore, we believe that when RIVC resection is combined with multiple organ resection, the operative duration is relatively long, and the blood loss volume is relatively large, even if there is a sufficient collateral circulation, the IVC should be reconstructed.

\section{Conclusions}

This study illustrates the surgical technique and shortand long-term outcomes of RIVC resection without reconstruction due to complex hepatic lesions inducing a rich collateral circulation. Although this study was limited by the number of cases and the follow-up duration, we recommend this procedure for use in ERAT (liver autotransplantation), Budd-Chiari syndrome, and primary IVC tumors but recommend that the surgeon think twice before not rebuilding the IVC.

\section{Supplementary information}

Supplementary information accompanies this paper at https://doi.org/10. 1186/s12893-020-00720-z.

Additional file 1: Figure S1. The main preoperative assessment and surgical techniques for retrohepatic inferior vena cava (RIVC) resection without reconstruction in ex vivo liver resection and autotransplantation (ERAT). a. preoperative imaging assessment of the extent of hepatic echinococcosis. b. shows the IVC blocked in back-table preparation. c. the treatments of inferior vena cava in the anhepatic phase. $d$. after the completion of the pipeline's reconstruction, the liver blood supply was good.

\section{Abbreviations}

ERAT: Ex vivo liver resection and autotransplantation; HAE: Hepatic alveolar echinococcosis; IVC: Intraabdominal inferior vena cava; RIVC: Retrohepatic inferior vena cava

Acknowledgments

I need to thank Zhenru Wu for her help with our illustrations.

\section{Authors' contributions}

YXW, WT and WWT collected and performed the data analysis and contributed to the writing of the manuscript. $\mathrm{KJ}$ and $\mathrm{HB}$ performed the literature search and statistical analyses. YXW, WT, KJJ and HB, interpretation of data, contributed to the discussion and final approval of the manuscript. All authors have read and approved the final version of the manuscript.

\section{Funding}

This research was supported by the Science and Technology Program of Sichuan Science and Technology Department (No. 2019YFS0029, 2019YFS0529), the National Natural Science Foundation of China (No. 81770566) and the New Medical Technology Foundation of West China Hospital of Sichuan University (No. XJS2016004). Corresponding author WWT is the guarantor. The funding body financed the costs of the study and contributed to the design of the study, interpretation of data, and revising the manuscript

\section{Availability of data and materials}

The datasets used and/or analysed during the current study are available from the corresponding author on reasonable request.

\section{Ethics approval and consent to participate}

This study was approved by the Ethics Committee of West China Hospital of Sichuan University (No. 2017-38) and was performed in accordance with the Declaration of Helsinki. All patients and their families signed informed consent and surgical consent before surgery. Patient signed publicly issued consent form (name, ID number and address cannot be provided; gender, age and clinical data are available).

\section{Consent for publication}

Written informed consent was obtained from the patients and/or their legal guardians for publication, and any accompanying images, sex, age of these patients.

\section{Competing interests}

The authors declare that they have no competing interests.

\section{Author details}

${ }^{1}$ Department of Liver Surgery \& Liver Transplantation Center, West China Hospital of Sichuan University, 37 Guoxue Road, Chengdu 610041, P. R. China. ${ }^{2}$ Department of Vascular Surgery, West China Hospital of Sichuan University, Chengdu, P. R. China.

Received: 6 October 2019 Accepted: 18 March 2020

Published online: 24 March 2020

References

1. Bi Y, Chen H, Ding P, et al. Comparison of retrievable stents and permanent stents for Budd-Chiari syndrome due to obstructive inferior vena cava. Gastroenterol Hepatol. 2018;33(12):2015-21. https://doi.org/10.1111/jgh. 14295.

2. Yang $X$, Qiu $Y$, Huang B, et al. Novel techniques and preliminary results of ex vivo liver resection and autotransplantation for end-stage hepatic alveolar echinococcosis: a study of 31 cases. Am J Transplant. 2018;18(7) 1668-79. https://doi.org/10.1111/ajt.14621.

3. Beldi G, Vuitton D, Lachenmayer A, et al. Is ex vivo liver resection and autotransplantation a valid alternative treatment for end-stage hepatic alveolar echinococcosis in Europe? J Hepatol. 2019;70(5):1030-1. https://doi. org/10.1016/j.jhep.2018.12.011.

4. Aji T, Dong JH, Shao YM, et al. Ex vivo liver resection and autotransplantation as alternative to allotransplantation for end-stage hepatic alveolar echinococcosis. J Hepatol. 2018:69(5):1037-46. https://doi. org/10.1016/j.jhep.2018.07.006. 
5. Shen S, Kong J, Qiu Y, et al. Ex vivo liver resection and autotransplantation versus allotransplantation for end-stage hepatic alveolar echinococcosis. Int J Infect Dis. 2019;79:87-93. https://doi.org/10.1016/j.jij.2018.11.016.

6. Yoon YI, Lee SG, Moon DB, et al. Surgical techniques and long-term outcomes of living-donor liver transplantation with inferior vena cava replacement using Atriocaval synthetic interposition graft for Budd-Chiari syndrome. Ann Surg. 2019;269(4):e43-5. https://doi.org/10.1097/SLA. 0000000000002847.

7. Wachtel H, Jackson BM, Bartlett EK, et al. Resection of primary leiomyosarcoma of the inferior vena cava (IVC) with reconstruction: a case series and review of the literature. J Surg Oncol. 2015;111(3):328-33. https:// doi.org/10.1002/jso.23798.

8. Qiu Y, Yang X, Shen $\mathrm{S}$, et al. Vascular infiltration-based surgical planning in treating end-stage hepatic alveolar echinococcosis with ex vivo liver resection and autotransplantation. Surgery. 2019;165(5):889-96. https://doi. org/10.1016/.jsurg.2018.11.007.

9. Kern P, Wen H, Sato N, et al. WHO classification of alveolar echinococcosis: principles and application. Parasitol Int. 2006;55(Suppl):S283-7. https://doi. org/10.1016/j.parint.2005.11.041.

10. Botrugno I, Gruttadauria S, Li PS, et al. Complex hydatid cysts of the liver: a single center's evolving approach to surgical treatment. Am Surg. 2010; 76(9):1011-5.

11. Wen H, Vuitton L, Tuxun T, et al. Echinococcosis: Advances in the 21st Century. Clin Microbiol Rev. 2019;32(2). https://doi.org/10.1128/CMR.0007518.

12. Yang $X$, Qiu $Y$, Wang $W$, et al. Risk factors and a simple model for predicting bile leakage after radical hepatectomy in patients with hepatic alveolar echinococcosis. Medicine (Baltimore). 2017;96(46):e8774. https://doi.org/10. 1097/MD.0000000000008774.

13. Jaiswal P, Jaiswal R, Attar BM, et al. Hepatobiliary and pancreatic: massive hepatic cystic echinococcosis compressing inferior vena cava. J Gastroenterol Hepatol. 2018;33(2):339. https://doi.org/10.1111/jgh.14038.

14. Du C, Liu Z, Yang X, et al. Hepatectomy for patients with alveolar echinococcosis: long-term follow-up observations of 144 cases. Int J Surg. 2016;35:147-52. https://doi.org/10.1016/j.ijsu.2016.09.094.

15. Shen S, Kong J, Zhao J, et al. Outcomes of different surgical resection techniques for end-stage hepatic alveolar echinococcosis with inferior vena cava invasion. HPB (Oxford). 2019;21(9):1219-29. https://doi.org/10.1016/j. hpb.2018.10.023.

\section{Publisher's Note}

Springer Nature remains neutral with regard to jurisdictional claims in published maps and institutional affiliations.

Ready to submit your research? Choose BMC and benefit from:

- fast, convenient online submission

- thorough peer review by experienced researchers in your field

- rapid publication on acceptance

- support for research data, including large and complex data types

- gold Open Access which fosters wider collaboration and increased citations

- maximum visibility for your research: over $100 \mathrm{M}$ website views per year

At $\mathrm{BMC}$, research is always in progress.

Learn more biomedcentral.com/submissions 